\title{
Towards a More Proactive Method
}

Regulating Public Opinion on Chinese Microblogs under Xi's New Leadership

Angela Ke Li

\section{(2) OpenEdition}

\section{Journals}

Electronic version

URL: http://journals.openedition.org/chinaperspectives/6840

DOI: 10.4000/chinaperspectives.6840

ISSN: 1996-4617

\section{Publisher}

Centre d'étude français sur la Chine contemporaine

\section{Printed version}

Date of publication: 1 December 2015

Number of pages: 15-23

ISSN: 2070-3449

\section{Electronic reference}

Angela Ke Li, «Towards a More Proactive Method», China Perspectives [Online], 2015/4 | 2015, Online since 01 January 2017, connection on 28 October 2019. URL : http://journals.openedition.org/ chinaperspectives/6840 ; DOI : 10.4000/chinaperspectives.6840 


\title{
Towards a More Proactive Method
}

\author{
Regulating Public Opinion on Chinese Microblogs under Xi's New Leadership
}

\author{
ANGELA KE LI
}

\begin{abstract}
Drawing upon policy analysis and textual analysis of official microblogs, this paper describes how Xi's new leadership regulates public opinion and public emotion in Chinese microblogs. The paper argues that the advent of the Xi Jinping administration demonstrates much more aggressive ideological demands. On the one hand, the new leadership has increasingly ramped up its efforts on censoring information and repressing critical public opinion. On the other hand, however, it has paid more attention to proactively guiding public opinion on the Internet. New strategies, represented by cultivating self-discipline among Internet users, repressing the insubordinate and wooing obedient public opinion leaders, establishing cooperation between official microblogs, and eliminating emotional outpourings in the microblogsphere have been used in Xi's new ideological campaign to repress Internet rumours and sanitise critical public discourse.
\end{abstract}

KEYWORDS: Internet policy, Xi's leadership, censorship, guiding public opinion and emotion, Chinese microblog.

\section{Introduction}

The last two decades have seen the exponential growth of the Chinese Internet and accordingly an explosion of studies on the Chinese Internet. It is universally agreed that the rapid growth of the Internet has brought profound changes to the Chinese political and social landscape. Within that general framework, there has been intense debate about whether and how greater access to information facilitated by the versatile and dispersed nature of the Internet encourages political expression and democracy in China. On one pole, scholars optimistically argue that by multiplying the amount of available information and providing individuals with the means to disseminate their opinions, the Internet has become a democratising force that will undermine the Party's authoritarian rule. (1) They argue that those new features - enabled by the technological advantages of the Internet - are particularly significant for China, where citizens previously had little opportunity for unconstrained public expression or access to free and uncensored information. (2)

In contrast to this optimistic view, others tend to dwell on the way that the state represses and controls the Internet. These clusters of scholarship argue that while the explosion of ICT-enabled political communication poses huge challenges to the state's monopoly on information, the state has responded to the challenge through draconian control over the flow of information. Standing in this pole, existing scholarship provides ample explanations of how the state has responded to the new challenges through various controlling measures, such as setting a variety of legal instruments, establishing dozens of new government agencies in charge of regulating different aspects of the Internet, and introducing technology to censor information supposedly detrimental to the interests of the state and social security. ${ }^{(3)}$

Whether pessimistic or optimistic, scholars studying the Chinese Internet have demonstrated the dual impact of the phenomenal growth of the Chinese Internet: on the one hand, there is increasing diffusion of thought and openness of information; and on the other hand, there is an expansion of the CCP's governing mechanism over online information.
Abundant scholarship shows that the CCP's direct control over online information is pervasive and sophisticated. It has introduced various levels of technical control, comprised of multiple layers of legal regulations and involving numerous state agencies and thousands of public and private personnel. (4) Institutionally, it is estimated that at least 12 government agencies - functioning in a variety of ways - are involved in censoring the Internet, among which the most important one is the State Internet Information Office (SIIO). Established in 2011, the office is notably in charge of launching online political campaigns and supervising online content management. ${ }^{(5)}$ The chief of the SIIO, Lu Wei, deserves scholarly attention. Since taking over the SIIO in 2013, he has demonstrated a canny awareness of the Internet and social media and has also proactively tightened control over online public opinion. (6)

Technologically, China has established one of the largest and most sophisticated Internet monitoring systems in the world to censor and manipulate unfavourable information on the Internet. Framing it as "networked authoritarianism," some scholars explain the parallel between the scale of information on the Internet on the one hand and information censorship on the other. While a wide range of information about social problems or injustices

1. For example, Yang Guobin, "Online Activism," Journal of Democracy, Vol. 20, No. 3, 2009, pp. 3336; Ashley Esarey and Xiao Qiang, "Digital Communication and Political Change in China," International Journal of Communication, No. 5, 2011, pp. 298-319; Zheng Yongnian, Technological Empowerment: The Internet, State, and Society in China, Palo Alto, CA, Stanford University Press, 2007.

2. Xiao Qiang, "The Rise of Online Public Opinion and its Political Impact," in Susan Shirk (ed.), Changing Media and Changing China, Oxford, Oxford University Press, 2011, pp. 77-91.

3. Anne Marie Brady, Marketing Dictatorship: Propaganda and Thought Work in Contemporary China, Lanham, MD, Rowman \& Littlefield, 2008.

4. Sheng Ding, "Informing the Masses and Heeding Public Opinion: China's New Internet-Related Policy Initiatives to Deal with its Governance Crisis," Journal of Information Technology \& Politics, Vol. 6, No. 1, 2009, pp. 31-42.

5. Xinhua, "China Set Up State Internet Information Office," China Daily, 4 May 2011, www.chinadaily.com.cn/china/2011-05/04/content_12440782.htm (accessed on 10 June 10, 2015).

6. Paul Mozur and Jane Perlez, "Gregarious and Direct: China's Web Doorkeeper," New York Times, 1 December 2014,www.nytimes.com/2014/12/02/world/asia/gregarious-and-direct-chinas-webdoorkeeper.html (accessed on 2 January 2015). 
appears on websites, the sole ruling Party remains in control over information to such a degree that no information can challenge state power. In the same vein, while people sometimes feel a much greater sense of freedom to express their opinion, Internet users who voice overly critical opinions that the rulers see as threats are systematically jailed. (7)

The logic underlying the explicit and direct control over online information is to ensure that the information that circulates online will not challenge Party authority. However, beneath the surface of the constantly increasing and intensifying control measures is a rising level of public selfexpression and emerging consciousness of "participative citizenry" in China. ${ }^{(8)}$ By virtue of various strategies, notably political satire or ironic use of politically correct language, insubordinate Chinese Internet users successfully skirt censorship and voice prohibited opinions. ${ }^{\left({ }^{9}\right)}$

Realising that regulating public opinion through total control or repression seems to yield poor returns on effort in the new technology environment, the Chinese government has attached increasing importance to guiding public opinion toward positions favoured by the CCP leadership. Two examples stand out in representing the CCP's efforts to guide public opinion: paid web commentators and government microblogs. As early as the mid-2000s, the CCP regime appointed thousands of commentary teams to disseminate pro-Party views. The goal was to create the impression of a strong tide of social opinion endorsing the government. To address public opinion and demands on the Internet, the Chinese Party-state later actively incorporated microblogs into their administrative operations as a form of e-government. Official microblogs were designed to release information, interact with the masses, and respond to public demands. ${ }^{(10)}$ The first government microblog was launched by Yunnan's provincial government in November 2009. (11) After that, numerous official microblogs were launched and attracted extensive social attention. By 2013 , more than 258,737 government microblogs had been set up, including 183,232 government agency microblogs and 75,505 official microblogs. (12)

While there was a surge in the employment of Internet commentators and official microblogs to guide online public opinion, growing speculation about the efficiency of those measures guiding online public opinion has emerged in current literature. The strategy of recruiting pro-Party commentators to counter oppositional online opinions was quickly identified by ordinary people. Official microblogs were considered top-down information relay tools rather than as interactive platforms with ordinary people. The effectiveness of the microblogs was therefore questioned in respect of enhancing direct exchanges between the Party-state and netizens. (13) Surveys among Chinese netizens have also revealed that Chinese government microblogs are considered a state-centric model of online Party propaganda tool. (14)

The difficulty of controlling public opinion partly resulted from the fact that the Internet has increasingly become the first place where news related to official corruption, governmental maladministration, property and labour rights violations, and conflicts between the underprivileged and the powerful have appeared. ${ }^{(15)}$ These issues, touching on what ordinary Chinese people are most concerned about, can quickly go viral and turn into a cause célèbre that sparks emotional outpourings against social problems on the Internet. For example, recent years witnessed the case of Wenzhou Train Crash on 23 July 2011, Deng Yujiao on 10 May 2009, (16) and the Yihuang self-immolation incident on 10 September 2010, in which netizens expressed intense outrage towards official malfea- sance. ${ }^{(17)}$ The accumulating online mobilisation and public discontent led to a decline in the credibility of the government and threatened the Party-state's legitimacy. ${ }^{(18)}$

The advent of the Xi jinping regime represents a sharp new turn in the political climate, with the government exercising increasing levels of control over public discourse. While the preceding Hu-Wen leadership also tightened control over the Internet, the new leadership has proven much more aggressive in its ideological demands. What is more, in order to remedy the government's deteriorating credibility resulting from the public opinion crisis, the central government has adopted new tactics to maintain its influence over microblogs, focusing on regulating online sentiment such as resentment against social inequality and official corruption. Firstly, the Chinese government has engaged in a new round of ideological campaigns among public opinion leaders. On the one hand, the new regime has repressed public opinion leaders who voice critical opinions; on the other hand, however, it has wooed obedient public opinion leaders to take the initiative to uphold the Party's ideology on the Internet. Secondly, the new regime has paid renewed attention to appeasing public indignation and purging negative emotion from the Internet. The fresh strategy is in line with the Party's new policy regarding Internet regulation, which calls for developing a favourable and healthy cyberspace. Under the slogan of purifying cyberspace, the Internet information management advocated by $\mathrm{Xi}$ jinping focuses on rectifying the chaos of an Internet full of rumours and public resentment. ${ }^{(19)}$

7. Mackinnon Rebecca, "China's Networked Authoritarism," Journal of Democracy, Vol. 22, No. 2, 2011, pp. 32-46.

8. Susan Shirk (ed.), Changing Media, Changing China, Oxford, Oxford University Press, 2011, p. 15.

9. Yang Guobin, The Power of the Internet in China: Citizen Activism Online, New York, Columbia University Press; Perry Link and Xiao Qiang, "From 'Fart People' to Citizens," Journal of Democracy, Vol. 24, No. 1, 2013, pp. 79-85; Herold David Kurt and Marolt Peter (eds), Online Society in China: Creating, Celebrating, and Instrumentalising the Online Carnival, London, Routledge, 2011; Yang Guobin, "Emotions and Movements," in George Ritzer (ed.), The Blackwell Encyclopedia of Sociology, Vol. 3, Oxford, Blackwell Publishing, 2007, pp. 1389-1392.

10. Nele Noesselt, "Microblogs and the Adaption of the Chinese Party-State's Governance Strategy," Governance, Vol. 27, No. 3, 2014, pp. 449-468.

11. "Yearender: Officials Surge to Microblogging as Government Departments Adopt New Dialogs with Public," Xinhua, 13 December 2011, http://news.xinhuanet.com/english/china/201112/13/c_131304520.htm (accessed on 12 June 2015).

12. "2013 nian Zhongguo zhengwu weiboke ping zhan baogao fabu: woguo zhengwu weiboke shuliang jiao shangnian zengzhang 46\%" (2013 Annual Report of Chinese Government Microblog: Government Microblog is Increasing by 46\%), Xinhua, 8 April 2014, http://news.xinhuanet.com/ politics/2014-04/08/c_1110140942.htm (accessed on 9 November 2015).

13. Jesper Schlæger and Jiang Min, "Official Microblogging and Social Management by Local Governments in China," China Information, Vol. 28, No. 2, 2014, pp. 189-213.

14. Hu Yong, "What Government Microblogs Do and Don't Mean," China Digital Times, 22 May 2011, http://chinadigitaltimes.net/2011/05/hu-yong-what-government-microblogs-do-and-don't-mean (accessed on 11 July 2014).

15. Xin Xin, "The Impact of Citizen Journalism on Chinese Media and Society," Journalism Practice, Vol. 4, No. 3, 2010, pp. 333-344.

16. Deng Yujiao, a young waitress in a karaoke bar in a small town of Hubei Province, stabbed a local official to death during an attempted rape. The story was discussed on the Internet by netizens in a radical and emotional tone. Netizens expressed great sympathy towards Deng Yujiao and regarded her as a heroine who bravely resisted the local official, who in turn symbolised the power of the government.

17. Tong Jingrong, "The Defense of Journalistic Legitimacy in Media Discourse in China: An Analysis of the Case of Deng Yujiao," Journalism, February 2014, pp. 1-18; Maria Bondes and Günter Schucher, "Derailed Emotions:The Transformation of Claims and Targets During the Wenzhou Online Incident," Information, Communication \& Society, Vol. 17, No. 1, 2014, pp. 45-65.

18. Yang Guobin, "Technology and Its Contents: Issues in the Study of the Chinese Internet," The Journal of Asian Studies, Vol. 70, No. 4, 2011, pp. 1043-1050.

19. "Xi Jinping: Ba woguo cong wangluo daguo jianshe chengwei wangluo qiangguo" (Xi Jinping: Building China as a Country with a Powerful Internet), Xinhua, 27 February 2014, http://news.xinhuanet.com/politics/2014-02/27/c_119538788.htm (accessed on 25 May 2014). 


\section{Research Method}

This paper intends to illustrate how $\mathrm{Xi}$ and the current establishment have employed new tactics to manipulate public opinion and public emotion on microblogs in a more proactive way. To this end, I have used empirical data from documentary analysis and journalists' analysis. Some government and Party documents were acquired during my participation and observation in the investigative reporting team of a Chinese online news outlet from December 2013 to April 2014 for my research project exploring Chinese investigative journalism in the new digital era. Most government and Party documents were circulated within official departments. I acquired them from political journalists at this online news outlet when I did in-depth interviews with them. With their expertise in reporting on official policies and conducting interviews with high-ranking government officials, these political journalists could gain access to internally-circulated documents and the most updated government policies. In addition, with its focus on critical and investigative reporting, the newspaper was particularly affected by information control on the Internet, because the Internet is a great source of story leads and news resources for investigative journalists. As a result, journalists are particularly sensitive to changes in Internet policy. In such situation, the official documents they obtained and the up-to-date policies they acquired could be considered the latest, most authoritative, and most valuable sources for studying new trends in public opinion management on the Internet. The documents were selected as relevant to the most notable fresh strategies used by the new regime to regulate online public opinion and public emotion. Since these documents were for internal circulation only, I am unable to clearly identify the name of the documents and the institutions that published them in order to protect the privacy of the journalists.

It should be noted that I am constrained by the limited documents that I could gain access to, which prevented me from getting all the new Internet policies. However, what I discuss here are the policies that represent the newest adjustments of the current regime in regulating online public opinion and public emotion in the microblogsphere.

Some other documentary sources were public information that could be accessed on the Internet. This predominantly includes data from the People's Daily Public Opinion Monitoring Room and declarations by officials of government institutions. Launched by People's Daily in 2008, the Public Opinion Monitoring Room is China's first professional organisation aimed at collecting, monitoring, and analysing nationwide public opinion on the Internet. Through mapping the whole picture of online public opinion, the room is designed to provide sources for making more effective policies for controlling information. The room has benefited from its identity as a Party organ, which allows it solicit views from experts and professionals with backgrounds in communications, sociology, economics, public management, and mathematics. In addition, the large scale of public opinion the room monitors and the advanced technology of collecting and processing information facilitate the room's production of relatively authoritative data, which has also become an important source for scholars who explore the Chinese Internet. Regarding official declarations, all of them came from authoritative Party-organ newspaper to ensure their accuracy and authenticity. The declarations were selected as the most relevant to my research focus.

Represented by People's Daily, official microblogs were also important to me in illustrating my arguments in this paper. In the new campaign to reg- ulate online information, People's Daily is a bellwether vested with the responsibility of leading the official voice and coordinating with other official microblogs to uphold the Party's ideology on the Internet. I tracked every microblog posted by People's Daily from July 2012 to December 2014. I downloaded each day's People's Daily microblog for my easy reference.

It is true that the Xi administration has issued various policies on Internet regulation. However, this paper only discusses the newest ones that are relevant to the focus of my paper. What I have illustrated here should be enough to support my argument. By mapping the new policies of the $\mathrm{Xi}$ regime on regulating public opinion and public emotion, this paper hopes to lay the foundation for further scholarship.

\section{Seven bottom-line policy and Six objectives policy}

On 10 August 2013, the State Internet Information Office issued a policy of Seven bottom lines of Internet information as the major guidance for the new ideological campaign on online public opinion. (20) According to People's Daily, the Seven bottom lines were:

The bottom-line of enhancing the socialist system; the bottom-line of upholding national interest; the bottom line of obeying laws and regulations; the bottom-line of protecting citizen's legal rights; the bottom line of maintaining social and public order; the bottom-line of promoting social ethics and virtue; the bottom-line of disseminating facts and truths. (21)

The Seven bottom lines were described as "high voltage power lines" or "the boundary of a political mine-field" that anyone should not touch or step into when releasing information and opinions on the Internet. (22)

The proposal of Seven bottom lines of online communication is powerful. Firstly, it is a management method for traditional media adapted to the new media space. The authorities have set minefields for traditional media, which make journalists cautious when reporting sensitive political-social problems. These minefields are both visible and invisible so that journalists practice self-censorship to ensure that their coverage won't be deemed too aggressive. Nowadays, the bottom-line is also set for ordinary people to prevent them from voicing critical opinions on the Internet. If the practice of censoring and deleting online information includes passive and ex post strategies, the establishment of bottom lines is a pre-emptive measure that forces ordinary people to conform to regulation and stops them from posting information critical of the Party's ideological hegemony. What is more, the definition of the bottom line is so vague that it is difficult to judge what types of information will (or will not) violate the bottom-line regulation. Such ambiguity may lead to self-censorship when ordinary people experiment with online communication. ${ }^{(23)}$

20. "Zhongguo hulianwang dahui changyi gongshou 'qi tiao dixian'" (China Internet Conference Advocates for Following Seven Bottom Lines), Xinhua, 15 August 2013, http://news.xinhuanet.com/ politics/2013-08/15/c_116961278.htm (accessed on 13 June 2015).

21. "Gongshou 'qi tiao dixian' zhuzao jiankang wangluo huanjing" (Holding Seven Bottom Lines and Creating a Healthy Online Environment), People's Daily, 15 August 2013, http://opinion.people.com.cn/BIG5/8213/368023/index.html (accessed on 25 May 2014).

22. Ibid.

23. Perry Link, "China: The Anaconda in the Chandelier," New York Review of Books, Vol. 49, No. 6, 2002, pp. 13-20. 
Along with the Seven bottom lines, new rules have been implemented to punish critical netizens. On 8 September 2013, the Chinese Supreme People's Court and Supreme People's Procuratorate issued a judicial interpretation stating that people who post false information on the Internet may face up to three years in prison if the posting is viewed more than 5,000 times or re-tweeted 500 times. ${ }^{24)}$ The new rule forces ordinary microblog users to think carefully before they post opinions or emotional remarks, which could easily be regarded as false information. Moreover, individual microblog users have no control over how many times a post is viewed and re-tweeted, so the new policy increases pressure towards conformity.

To further show the government's determination to take up a national campaign to sanitise Internet expression, the State Internet Information Office announced Six objectives that the campaign intends to achieve. (25) According to Lu Wei, the leader of the Office, the six objectives are as follows:

First, listening to public opinion and appeasing negative emotional outpourings against government legitimacy; second, promoting advanced socialist culture and upholding truth, virtue, and courtesy; third, fighting against Internet rumours; fourth, accelerating the enactment of Internet laws and regulations; fifth, safeguarding Internet security; finally, developing Internet technology and leading to a boom in the Internet industry. ${ }^{(26)}$

It seems apparent that the new leadership, like its predecessors, is still deeply anxious about the Internet's subversive effect of facilitating mobilisation that could turn against CCP rule. As a result, the government has continued to tighten control over the Internet. However, through the lens of the Seven bottom-lines and Six objectives, I argue that the new regime is not only continuing its heavy-handed control over information but is also paying more attention to emotional outpourings. The crude practices of blocking and censoring online information will continue, but the regime will make a greater effort to lead Internet users to give up expressing angry and aggrieved emotions.

\section{Anti-public opinion leader policy: The time of Big Vs has passed}

Microblogs provide the Chinese people with unprecedented opportunities to engage in public debates about political and social issues closely related to their lives. The increasing amount of information on microblogs has weakened the influence of Party media in setting the news agenda. What is more, public debates about hot-button issues on the Internet could transform a news event into a cause célèbre that sparks emotional outpouring. The mix of critical public opinion and emotional catharsis has aroused CCP leaders' uneasiness over the destabilising effect of the Internet and has motivated them to continue investing heavily in mechanisms to regulate online information and public expressions.

In order to make control over information more effective, the new leadership put a new emphasis on public opinion leaders (also known as "Big $\left.V s^{\prime \prime}\right)$, who are mostly liberal and outspoken and have a profound influence on shaping the agenda of public debate on the Internet. Compared with the myriad grass-roots microbloggers, public opinion leaders are much fewer. However, they are much more powerful than ordinary people in setting the agenda of public discussions and debates, because their identity gives personal credibility to information and attracts immense attention. Some Big Vs are bold enough to articulate what others do not dare to say under political censorship. (27) By targeting public opinion leaders, the new leadership has found an easy but effective way to control online critical discourse.

The People's Daily Public Opinion Monitoring Room has pointed to four powerful groups that compete for control over the news agenda in the microblog sphere. According to them, these are government microblogs, public opinion leaders, market-oriented media, and Party media, among which online public opinion leaders are the most likely to release critical opinions against the Party. (28)

Realising their significance in setting the news agenda, and in hopes of better controlling information on the Internet, the authorities for the first time launched measures specifically designed to control online public leaders. Firstly, the government set criteria to clarify who is (or is not) a public opinion leader. The government made a list of 300 public opinion leaders based on three criteria: number of followers (at least 100,000 fans), number of times that they were quoted in traditional media, and how radical their opinions were. The government also provided profiles of these 300 public opinion leaders. They are predominately male and 40 to 60 years old. Nearly $70 \%$ of them hold a Master's degree or above. A majority of those public opinion leaders work in the broadly defined media field, such as traditional media institutions, the film industry, the book publishing industry, advertising companies, and so on. They earn an annual income of 100,000 to 600,000 yuan and thus can be regarded as middle-class in today's China. The defining feature of online public opinion leaders is that they keep close contact with the traditional media. As a consequence, they are particularly willing to strategically use the Internet to expose news stories that are banned from reporting in the traditional media. ${ }^{(29)}$

The ideological campaign targeting influential (micro)bloggers on the Internet started with the Conference of Online Public Opinion Leaders, held by the State Internet Information Office on 15 August, 2013. (30) The conference required Internet celebrities to take social responsibility for spreading positive energy and to comply with the Seven bottom lines when posting information or expressing opinion on the Internet. Lu Wei, director of the State Internet Information Office, proposed six expectations concerning the Big Vs on the conference:

24. Yang Guobin, "The Return of Ideology and the Future of Chinese Internet Policy," Critical Studies in Media Communication, Vol. 31, No. 2, 2014, pp. 109-113.

25. "Guojia hulianwang xinxiban: rang wangluo kongjian qinglang qilai yao shixian 'liu da mubiao"" (Six Objectives to Achieve in order to Make Internet Sphere Clean), Xinhua, 30 October 2013, http://news.xinhuanet.com/politics/2013-10/30/c_117939405.htm (accessed on 12 June 2015).

26. "Wangluo kongjian ruhe qinglang qilai. Lu Wei tichu 'liu ge mubiao'" (How Internet Sphere Becomes More Purified and Clean. Lu Wei Puts Forward the Six Objectives to Achieve), Xinhua, 30 October 2013, http://news.xinhuanet.com/politics/2013-10/30/c_117927908.htm (accessed on 25 May 2014).

27. Tong Yanqi and Lei Shaohua, "War of Position and Microblogging in China," Journal of Contemporary China, Vol. 22, No. 80, 2013, pp. 292-311.

28. Internally-circulated political document acquired during my fieldwork at the above-mentioned Chinese online news outlet when I did in-depth interviews with political journalists there. The document is about new recommendations to regulate online public opinion. It provided full descriptions of the landscape of public opinion on the Internet, particularly on the microblogsphere, who dominates the public opinion leaders on the microblogsphere, the profile of microblog users, and so on. To protect the privacy of the journalists, I cannot clearly identify the title of the document and which institution published it.

29. Ibid. To protect the privacy of the Big Vs, I cannot reproduce the list here.

30. "Zhongguo hulianwang dahui changyi gongshou 'qi tiao dixian'" (The Conference of Chinese Public Opinion Leaders Advocated for Following Seven Bottom Lines), People's Daily, 16 August 2013, http://media.people.com.cn/n/2013/0816/c40606-22584001.html (accessed on 12 June 2015). 
First, Big Vs - with large numbers of followers - should take the initiative to shoulder social responsibility; second, Big Vs are obliged to protect state interests, promote positive energy (31) and encourage netizens to contribute to China's rejuvenation; third, Big Vs should consciously promote advanced socialist culture and traditional Chinese virtue; fourth, Big Vs should take the lead in following laws and regulations; fifth, Big Vs should advocate social integrity and good faith; finally, Big Vs should maintain individual legitimate rights and interests and resist any activities that damage individual reputations and rights. (32)

In practice, for obedient public opinion leaders who are either unenthusiastic about social and political issues or willing to follow the Party line, the authorities have encouraged them to promote Party ideology and guide their followers to participate in online discussion in the politically correct direction. On the other side, the detention of some Big Vs such as Xue Manzi has served to intimidate potentially critical public opinion leaders. Xue Manzi, an Internet Big $\vee$ and Chinese-American venture capitalist was detained in Beijing on 23 August 2013. Although Beijing police officials claimed that Xue was detained on charges of soliciting a prostitute, some scholars have speculated that the real reason underlying his detention was probably his active and critical remarks on current affairs. ${ }^{(33)} \mathrm{Ac}$ cording to data provided by the Internet Opinion Monitoring Room under People's Daily, since the crackdown, the number of posts by a sampling of 100 public leaders declined by nearly $25 \%$ in September 2013 , only one month after the conference. ${ }^{(34)}$ Some scholars also noticed the phenomenon that Big Vs were less active than before. ${ }^{(35)}$

\section{Cultivating Medium Vs and planting positive information}

Ever since the Mao Zedong era, the methods used by CCP leaders to inculcate political loyalty and ideological conformity has reflected an acute awareness that peer groups have a greater impact on individual attitudes than authority figures. ${ }^{(36)}$ In the Hu administration, propaganda officials applied this insight to online information management by employing paid Internet commentators disguised as ordinary people to participate in public debates. Under Xi's leadership, online Medium Vs act as peers to guide public opinion. Medium Vs have verified accounts with moderate numbers of followers - less than Big Vs but far more than grassroots users. ${ }^{(37)}$ Although they are not as influential as Big Vs, Medium Vs' concerns and opinions about social and political issues can also attract considerable attention from ordinary Internet users. Generally speaking, Medium Vs are professors, high-ranking editors and journalists, or lawyers and experts. Because they're usually experts in various areas, their ideas can be considered authoritative in their own field. Therefore, the government cultivates Medium Vs ${ }^{(38)}$ to propagate the Party's line and support Party policies on controversial issues. ${ }^{(39)}$ Based on the current literature, we only know that the Party-state intends to promote Medium Vs on the microblogsphere. However, a series of question deserves further scholarly attention when more policies become available, such as the specific ways in which the regime cultivates Medium Vs and how Medium Vs lead public opinion on the Internet.

Compared with previous methods creating a wave of pro-Party voices through paid commentators, making use of Medium Vs is a more opaque and subtle way to influence public opinion, because ordinary people do not know that Medium Vs' opinions on social issues are following the Party's instructions. Much more importantly, planting positive online commentaries and influencing public opinion through Medium Vs are much more effective strategies than using paid commentators, because their identity as experts or intellectual elites give more authority to the opinions they espouse. By virtue of the new Internet management strategies, the new leadership expects the positive voices of official microblogs, allying with the voices of Medium Vs, could overwhelm critical voices on the Internet. Some scholars estimate that this round of Internet governance, aimed at courting or intimidating influential people on the Internet, is much harsher than ever before. ${ }^{(40)}$

\section{Government microblogs and guiding public opinion}

On 25 February 2014, Xi jinping organised the first conference of the newly-established Central Leading Group for Cybersecurity and Informatisation. Xi called for innovative methods to spread mainstream values, stimulate positive energy, and maintain proper guidance of online public opinion. Xi said:

We must be adept at guiding public opinion on the Internet. Doing a good job of guiding public opinion is a long-term mission. ${ }^{(41)}$

Guidance of public opinion on the Internet became the buzzword of the new leadership's policy over the Internet.

31. "Positive energy" is a new political campaign term initiated by President Xi Jinping. Generally speaking, positive energy refers to optimistic and inspiring content and attitudes as opposed to pessimistic and critical ones. The term has become China's newest catchphrase and is used not only in the realm of regulating "information" but also for other issues, such as international relations. For example, Xi urged injecting positive energy into Sino-US bilateral ties. According to Xi, positive energy means sharing more common interests than differences and disputes, because differences and disputes have a negative effect on the bilateral relationship. The term should be particularly understood as part of the new control lexicon of China's information and culture, because it is specifically used to repress dissent and negative news coverage and online comments. Cf. "'Positive Energy' in Musical Homage to First Couple," China Digital Times, 24 November 2014, http://chinadigitaltimes.net/2014/11/netizens-show-positive-energy-musical-homage-first-couple (accessed on 17 September 2015). While to some degree the phrase is new, the underlying meaning is in the very lineage of the long-standing propaganda language of reporting more positive stories and pro-Party news than negative stories and critical news. For example, the Chinese government is currently urging online public leaders and governments and companies in charge of supervising Internet sites to explore new ways of managing the virtual world with spreading positive energy as a main goal.

32. "Wangluo mingren shehui zeren luntan" (The Conference of Public Opinion Leaders), People's Daily, 18 August 2013, http://media.people.com.cn/GB/22114/367849/index.html (accessed on 11 July 2014).

33. Yang Guobin, "The Return of Ideology and the Future of Chinese Internet Policy," art. cit.

34. Song Shijing and Li Dandan, "'Rouxing' guanli bannian. Wangluo kongjian 'qinglangqilai'" (Regulating Internet in a Soft Way, Internet Sphere becomes Cleaned), Beijing News, 28 February 2014, http://epaper.bjnews.com.cn/html/2014-02/28/content_497090.htm?div=0 (accessed on 6 May 2014).

35. Wei Wuhui, "Weibo de hexin yong huqun: zhong V he xiao V" (Who Is the Dominant Users in Chinese Microblog), Tmtpost, 26 September 2013, www.tmtpost.com/66840.html (accessed on 13 June 2015)

36. Susan Shirk (ed.), Changing Media, Changing China, Oxford, Oxford University Press, 2011, p. 14.

37. Political document acquired during my fieldwork.

38. To protect the privacy of the Medium Vs, I cannot provide a list of their names.

39. Jiang Junfang, "Lianshou fuchi zhuanjiaxing 'zhong V'" (Supporting Medium Vs on the Microblog), Sichuan Daily, 1 December 2013, http://epaper.scdaily.cn/shtml/scrb/20131201/47846.shtml (accessed on 13 June 2015)

40. Chris Buckley, "Crackdown on Bloggers is Mounted by China," New York Times, 10 September 2013, www.nytimes.com/2013/09/11/world/asia/china-cracks-down-on-online-opinion-makers.html? pagewanted $=2 \& \_r=0$ (accessed on 6 May 2014).

41. "Xi Jinping zhuchi zhaokai xinxi wangluo anquan xinxi xiaozu shouxi huiyi" (Xi Jinping Held the Conference of the Central Leading Group for Cybersecurity and Informatisation), People's Daily, 27 February 2014, http://news.sohu.com/20140227/n395778590.shtml (accessed on 14 November 2015). 
Guidance of public opinion is not an innovative idea in the realm of the Party's media policy. ${ }^{(42)}$ It has been the centrepiece of propaganda work since the crackdown on the student movement in Tiananmen Square in 1989. ${ }^{(43)}$ Between the two extremes of enforcing/upholding ideologicallysound public opinion and repressing ideologically-critical public opinion, guiding public opinion is a more indirect, flexible, and subtle way of influencing and shaping public opinion. Guidance of public opinion tries to shift its focus from controlling what can be discussed (or not) to what people should think about current affairs. To be specific, when hot-button issues relevant to social problems spread on the Internet, the government tries to manipulate the angles and perspectives through which people think about them and attempts to divert ordinary people's attention from questioning and criticising the government by showing sympathy to the suffering of the people and by emphasising the hope for a better future.

Through the lens of the changing strategy of official microblogs, we may get a glimpse of how guidance of public opinion is practiced. In 2013, the CCP, across all levels and administrative departments, continued to struggle with microblogs. ${ }^{(44)}$ Compared with 2012, official microblogs increased by $46.42 \%$ (more than a quarter of million in total), among which microblogs held by government agencies increased by $61 \%$ and microblogs owned by individual officials increased by less than $20 \%$. ${ }^{(45)}$ Beyond the increase in the number of government microblogs, government microblogs enhanced cooperation and broke down isolation among themselves. In order to lead public opinion on emergencies and sensitive issues, the People's Daily allied itself with other Party media and government organs to establish a national microblog team. ${ }^{46)}$ The national microblog team is designed to respond in concert when hot issues spread on the Internet to amplify the voice of the Party and thus overpower the voices of netizens. ${ }^{(47)}$ Such collaboration promises to make the voice of the Party-state prevail and thus overshadow critical voices. The overwhelming voice of the Party could guide ordinary Internet users to discuss and comment on hot topics in a manner consistent with the Party's tone. For example, the People's Daily, Xinhua News, and CCTV News microblogs constituted the most important national microblog team, attracting more than 30 million followers. ${ }^{(48)}$ One notable case that reflected the working mechanism of national microblog team was the haze that blanketed China on 12 January 2013. The CCTV News microblog took the lead in responding to the pollution, reminding netizens at 9:09 AM that "haze has occurred in a number of cities nationwide, and please drive carefully." (49) At 9:45 AM, People's Daily followed up and repeated the content of CCTV News reminding people to drive safely. The People's Daily microblog also provided brief information on how to keep healthy in haze pollution. (50) On 13 January 2013, Xinhua News posted a microblog mentioning how to maintain balanced nutrition in haze pollution. ${ }^{(51)}$ Under the leadership of the three Party media, haze pollution became a hot-button issue on the microblogs. But the perspective used by the two microblogs guided netizens to focus on self-protection rather than on questioning or criticising the horrible environmental problems plaguing China. ${ }^{(52)}$

The government found the new strategy effective. According to data provided by People's Daily Public Opinion Monitoring Room, regarding issues drawing great attention and heated discussion since August 2013, the national microblog team was louder than any noise on the Internet. ${ }^{(53)} \mathrm{Zhu}$ Huaxin, the general secretary of the Monitoring Room, wrote an editorial on the China Youth Daily claiming that the national microblog team could follow the central government's stand on hot-button issues, which is instrumental to maintaining the authority and credibility of the central gov- ernment and enhancing the communication of the "main melody." (54) Using the figurative expression that "the national microblog team successfully recaptured the microphone on the Internet," Lu Wei held that the scenario of the government being questioned, criticised, or even abused has been successfully overturned. (55)

In addition to making the official voice louder on the Internet, government microblogs are also paying renewed attention to guiding public sentiment, an umbrella term that refers to the emotional and cognitive reaction of ordinary people to information. As I have mentioned, the Chinese (micro)blogosphere was characterised not only by the expression of liberal and critical opinions, but also by emotional outpourings, such as playfulness, sadness, resentment, grievance, and sympathy. For example, in the case of Deng Yujiao, when the facts were still unclear, netizens celebrated Deng Yujiao as a heroine who fought against a privileged official, whose death was considered well deserved. ${ }^{(56)}$ Therefore, this particular public opinion crisis was not only caused by the exposure of social problems on the Internet, but also by those problems churning up a tide of negative emotion and dissatisfaction that resulted in Internet users questioning leaders' governing capacity, criticising official malfeasance, or even mocking the Party's rule. To salvage sagging government credibility, the new leadership began to invest heavily in managing online emotion. The overriding goal of emotion management is to reduce negative emotional outpourings and make people sympathetic to the Party's agenda.

42. Alex Chan, "Guiding Public Opinion Through Social Agenda-Setting, China's Media Policy Since the 1990s," Journal of Contemporary China, Vol. 16, No. 53, 2007, pp. 547-559.

43. Qian Gang and David Bandurski, "China's Emerging Public Sphere: the Impact of Media Commercialization, Professionalism, and the Internet in an Era of Transition," in Susan Shirk (ed.), Changing Media, Changing China, Oxford, Oxford University Press, pp. 38-76.

44. Josh Rudolph, "Number of Government Weibo Accounts Soars," China Digital Times, 28 March 2013, http://chinadigitaltimes.net/2013/03/number-of-government-weibo-accounts-soars (accessed on 9 May 2014).

45. "2013 nian Zhongguo zhengwu weiboke ping zhan baogao fabu: woguo zhengwu weiboke shuliang jiao shangnian zengzhang 46\%" (2013 Annual Report of Chinese Government Microblog: Government Microblog is Increasing by $46 \%)$, art. cit.

46. "Weibo 'guojiadui' ruhe geng hao fa li" (How National Microblog Team Becomes Powerful on the Internet), Renmin wang, 2 December 2013, http://opinion.people.com.cn/n/2013/1202/c100323709708.html (accessed on 14 November 2015).

47. "2013 nian Zhongguo zhengwu weiboke ping zhan baogao fabu: woguo zhengwu weiboke shuliang jiao shangnian zengzhang 46\%" (2013 Annual Report of Chinese Government Microblog: Government Microblog is Increasing by $46 \%)$, art. cit.

48. "Weibo 'guojiadui' ruhe geng hao fa li" (How National Microblog Team Becomes Powerful on the Internet), art. cit

49. CCTV microblog about haze pollution on 12 January 2013, www.weibo.com/cctvxinwen? is_search $=1 \&$ visible $=0 \&$ key_word=\%E9\%9B\%BE\%E9\%9C\%BE\&is_tag=0\&profile_ftype $=1 \& p a g$ $\mathrm{e}=7$ \#feedtop (accessed on 7 June 2015).

50. People's Daily microblog about haze pollution on 12 January 2013, www.weibo.com/rmrb? is _search=1\&visible=0\&key_word=\%E9\%9B\%BE\%E9\%9C\%BE\&_s_tag=0\&profile_ftype=1\&page =7\#feedtop (accessed on 13 June 2015)

51. Xinhua News microblog about haze pollution on 12 January 2013, www.weibo.com/zhongguowangshi?is_search $=1 \&$ visible $=0 \&$ key_word=\%E9\%9B\%BE\%E9\%9C\%BE\&is_tag=0\&profile_f type $=1$ \&page $=4 \#$ feedtop (accessed on 13 June 2015).

52. "'Weibo guojia dui' qiangshi chengzhang" (The Burgeoning of the National Microblog Team), People's Daily, 18 March 2013, http://yuqing.people.com.cn/n/2013/0318/c210118-20822437.html (accessed on 13 June 2015)

53. Song Shijing and Li Dandan, "'Rouxing' guanli bannian. Wangluo kongjian 'qinglangqilai'" (Regulating Internet in a Soft Way, Internet Sphere becomes Cleaned), art. cit.

54. Pan Yuefei, "Weibo guojia dui: zhuda wenqing pai" (The Emergence of the National Microblog Team), Qianjiang Evening, 13 November 2012, http://qjwb.zjol.com.cn/html/2012-11/13/content_1854663.htm? div=-1 (accessed on 13 June 2015).

55. Ibid.

56. Tong Jingrong, "The Defense of Journalistic Legitimacy in Media Discourse in China: An Analysis of the Case of Deng Yujiao," art. cit., pp. 1-18. 
Specifically, the new emphasis on regulating public emotion can be detected through the transformation of official microblogs from a rigid propagandistic writing style to a much more energetic and literary form of expression. ${ }^{(57)}$ In practice, some official microblogs began using lyrical phrasing or comments that were warm, positive, and devoid of stiff official overtones. The lyrical phrases or comments in general were not official responses to or explanations of news events, but rather words crafted to comfort grieving people who were victims of these social problems.

A telling example is the development of the People's Daily microblog. Featuring a delicate rhetoric and inspirational writing, the People's Daily microblog has expressed sympathy toward those injured or killed in emergencies or to victims of social inequality. In addition to writing warm words, the People's Daily microblog also lights a candle and calls for prayers for the victims of natural disasters and social problems. At the same time, it calls on all Internet users to pray for a bright future. For example, in the case of the terrorist attack in Kunming (58) on 1 March 2014, People's Daily published several warm comments such as "Let us pray for the loss of life"; "Please light a candle and turn off the lights"; "Kunming, do not weep"; "May the deceased rest in peace"; "Kunming will always be beautiful, and we are with you, people of Kunming," and so on. ${ }^{(59)}$ It should be noted that People's Daily wrote nothing about how and why such terrible events happened and how the government dealt with the emergency. Nevertheless, the lack of key information related to the case did not cause dissatisfaction among netizens. Instead, those warm microblogs guided netizens to focus their attention on praying for the dead and injured rather than on the case per se. Similarly, when news stories related to social inequality or abuse of power are disseminated on the Internet, the People's Daily microblog comforts angry netizens with claims that tomorrow will be better. ${ }^{(60)}$ For example, in the case of aforementioned nationwide haze pollution on 11 January 2013, People's Daily commented that "this [air pollution] is not the life we want; while the present reality is grey China, a beautiful China should be expected in the future." (61) Moreover, the People's Daily microblog came up with a column entitled "Hello, tomorrow" aimed at facilitating netizens voicing their "Chinese dream" and propagating "positive energy." Proposed by Xi Jinping on November 2012, the "Chinese dream" became a new term within the system of Chinese socialist thought. Xi has described the Chinese dream as "national rejuvenation, improvement of people's livelihood, prosperity, construction of a better society and military strengthening." (62) Xi also encouraged ordinary people to achieve individual dreams and thus contribute to the revitalisation of the nation. The idea of the Chinese dream as a propaganda slogan is smart, because it can be extended to the national level as well as made specific at the individual level. In this, the Party-state's macroscopic Chinese dream to build a strong party and nation articulates little conflict with ordinary people's microscopic dreams of a good life. ${ }^{(63)}$ Therefore, although the Chinese dream is still a symbolic resource to enhance the Communist Party's ideological and political authority, the Party has managed not to present it in a top-down totalitarian and indoctrinating way. ${ }^{(64)}$

\section{Xi's image campaign and guiding public emotion}

Like his predecessor $\mathrm{Hu}$ Jintao, $\mathrm{Xi}$ Jinping has been keen to build an image as a warm leader and show his closeness to ordinary people on the Internet. To conduct his image campaign as an accessible leader, Xi has actively embraced the microblog platform. What is more, his microblog image campaign has been instrumental in leading public emotion on the Internet and contributing to the new round of online public opinion regulation.

There may be substantial differences between $\mathrm{Xi}$ and his predecessor in communicating with ordinary people through microblogs. In simple terms, Hu Jintao's online presence consisted of scheduling occasional online chat sessions with netizens on special occasions, such as People's Daily's 60th anniversary and sessions of the National People's Congress. Such interaction, rare and arranged in advanced, was like a political official's visit to the virtual chatroom of ordinary people. In comparison, $X i$ has attempted to appear online more frequently and in a more civilian guise. The Xi regime has creatively arranged to post Xi's casual visits and activities on social media rather than in state-run traditional media. Although information is still released through official microblog accounts, the shift from Party media, which definitely represent authoritative discourse and official ideology, to the communication platform of ordinary people benefits Xi's campaign as accessible leader in at least two aspects. First, it reduces the propagandistic tone. Second, Xi's mingling with the public is meant to show his spontaneous willingness to pay attention to ordinary people's lives rather than to arrange official inspections similar to the other formal activities a national leader engages in.

For example, on 29 December 2013, Xi ate steamed buns in an ordinary Beijing eatery called the Qing Feng Bun Shop. ${ }^{(65)}$ Videos and photos of Xi's bun excursion were first broadcast by ordinary people on microblogs and then reproduced on the state-run People's Daily, Xinhua News Agency, and CCTV News microblog accounts. The videos and photos on the microblogs quickly went viral on the Internet and received many positive comments from ordinary people, who not only appreciated $\mathrm{Xi}$ as a warm and accessible leader who queued up and ordered buns like ordinary people, but also felt excited to serve as primary information sources on Xi's visit. President $\mathrm{Xi}$ continued his campaign to be regarded as a warm leader by taking a stroll in Nan Luo Gu Xiang, a historic area of Beijing, on 25 February 2014.

57. Barry van Wyk, "The Chinese Government and Social Media," Danwei, 20 December 2012, www.danwei.com/the-chinese-government-and-social-media (accessed on 2 January 2015).

58. The Kunming Attack was a terrorist attack in Kunming, Yunnan Province, on 1 March 2014, which left 33 dead and more than 140 others injured. The attack was launched by Uyghurs.

59. People's Daily Microblog, http://weibo.com/rmrb?is_search=1\&key_word=\%E6\%88\%91\% E4\%BB\%AC\%E4\%B8\%8E\%E4\%BD\%A0\%E5\%90\%8C\%E5\%9C\%A8\#_0 (accessed on 1 January 2015).

60. People's Daily Microblog, http://weibo.com/rmrb?is_search=1\&key_word=\%E4\%BD\% A0\%E5\%A5\%BD\%2C\%E6\%98\%8E\%E5\%A4\%A9\#_0 (accessed on 6 January 2015).

61. People's Daily Microblog: http://weibo.com/rmrb?is_search=1\&visible $=0 \&$ key_word $=\% E 4 \% B D$ \%A0\%E5\%A5\%BD+\%E6\%98\%8E\%E5\%A4\%A9\&is_tag=0\&profile_ftype=1\&page=21\#feedtop (accessed on 13 June 2015).

62. "Xi Jinping zongshuji shenqing chanshu 'Zhongguo meng'" (General Secretary Xi Jinping Explains the Chinese Dream), Xinhua, 30 November 2012, http://news.xinhuanet.com/politics/201211/30/c_124026690.htm (accessed on 14 November 2015).

63. Yang Guobin, "The Return of Ideology and the Future of Chinese Internet Policy," art. cit:; Elizabeth Perry, "Cultural Governance in Contemporary China: 'Re-orienting' Party Propoganda," HarvardYenching Institute Working Paper Series, www.harvard-yenching.org/sites/harvardyenching.org/files/featurefiles/Elizabeth\%20Perry_Cultural\%20Governance\%20in\%20Contempo rary\%20China_0.pdf (accessed on 13 June 2015).

64. "My Chinese Dream," CNTV, http://people.cntv.cn/special/2013dream/shouye/index.shtml (accessed on 14 January 2015)

65. Fun Club of Learning From Xi on the Microblog: Qing Feng Bun Shop Tour in the microblog of Fan Club of Learning From Xi, http://weibo.com/u/3043581645?topnav=1\&wvr=6\&topsug=1\&is _search=1\&key_word=\%E5\%8C\%85\%E5\%AD\%90\#_rnd 1420502784117 (accessed on 5 January 2015). 
Xi's casual visit was again reported on microblogs rather than by traditional state-run media. ${ }^{(66)}$

In parallel with Xi's proactive use of social media to build his image, the microblog account "Fan Club of Learning from Xi," tasked with posting information about Xi's official trips and stories and photographs of $X i$ and his family members, was launched in November 2012. ${ }^{(67)}$ The nickname Pingping was used on the microblog instead of the formal and official name Present Xi Jinping when referred to Xi's family, previous educational and work experience, mottos, and favourite sports. ${ }^{(68)}$ Xi's strategic employment of social media to cultivate his image was highly relevant to the regime's new emphasis on regulating online public emotion.

Official and mainstream media have customarily been utilised by the CCP authorities for their own propaganda purposes and therefore represent official discourse. By contrast, social media are regarded as a platform empowering ordinary Chinese people with a voice. The immediacy of the microblog postings about Xi's visit, which appeared even earlier than in official media, created the illusion that ordinary people were closer to President $\mathrm{Xi}$ and that ordinary people could get information faster than official media. In a similar vein, unique information about Xi's family life on the microblog also bridges the gap between high-ranking officials and ordinary people. Xi's proactive accessing of the microblog is also aimed at alleviating pessimistic sentiments on the Internet and gauging public sentiment on the Chinese cyberspace. People's Daily Public Opinion Motoring Room commented:

Xi's image as a warm leader has been widely touted by ordinary Internet users. Dissemination of Xi's image and casual activity on social media has made a positive contribution to propagating the Party's ideology and putting pressure on jarring voices of criticism and emotional outpourings against government. ${ }^{(69)}$

While the microblog account was called "Fan Club of Learning from Xi," some media analyst conjectured that the microblog was not the work of real fans and was definitely not by ordinary grass-roots-level netizens. It looks more like part of a well-designed propaganda effort by either the central government or reporters from Party-run news media. ${ }^{\left({ }^{70}\right)}$ Although still propaganda, it is carried out in a much cleverer and more humanised way. ${ }^{(71)}$

Data from the People's Daily Public Opinion Monitoring Room revealed the effectiveness of this new tactic to regulate public opinion. Since August 2013 , negative comments on microblogs have declined by $63 \%$. ${ }^{(72)}$ Positive public opinion on the Internet has successfully overwhelmed negative voices, as measured in two ways: a decrease in social problems exposed by netizens on the Internet and in criticism against or emotional outpourings towards the government. ${ }^{(73)} \mathrm{A}$ number of public intellectuals have recently lamented the decline of critical discussion on social issues on Chinese microblogs following officials' tightening grip on them. ${ }^{(74)}$

\section{Conclusion}

This paper is about the government's new strategies to manipulate online public opinion since Xi Jinping came to power. Firstly, the new leadership has stepped up efforts to tighten its reins on information and public opinion on microblogging sites. In line with this, the new government proposed Seven bottom lines and Six objectives as the general policy guide- line. The proposal of "Seven bottom lines" represents a much more proactive way to regulate online public opinion. Bottom lines, such as "minefield" or "high voltage," were set for ordinary Internet users to stay clear of. However, the description of bottom lines is extremely vague and could provoke self-censorship among ordinary people. The strategy is the re-appropriation of management over traditional media adapted to the new media space, which tends to put new emphasis on self-discipline among individual Internet users. In addition to regulating ordinary people, the Chinese government for the first time aims at controlling the group of liberal and outspoken public opinion leaders (Big Vs), whose opinions on the Internet could attract intense attention and churn up a tide of public debate on hot-button issues. Aware of the power of public opinion leaders in shaping the public opinion trends, the government has on the one hand cracked down on some dissenting public opinion leaders while wooing the more docile ones to follow the Party line. The government has also intentionally indoctrinated Medium Vs with the Party's ideology and has them shoulder the responsibility of proactively promoting pro-government opinions and moulding online expression.

In order to save the public opinion crisis and remedy the government's deteriorating public credibility, the central government has adopted new tactics to uphold its influence on the Internet. In parallel with the core policy of promoting positive energy on the Internet and upholding the Chinese dream, the new tactics are primarily designed to appease public sentiment on the Internet. Therefore, by virtue of the national microblog team adding warm and sympathetic expression to government microblogs and Xi's image campaign as an accessible leader, government microblogs not only continue to amplify the official voice on the Internet but also attempt to channel public emotion.

In essence, the CCP has not given up its ingrained habits of censorship and control over online information, no matter how innovative and subtle the strategies it uses. However, as this paper suggests, there is a new trend of Internet strategy that has shifted from ex-post-facto deleting or censoring of unfavourable information towards a proactive and pre-emptive action that leads Internet users to post desirable information and actively eradicate critical and negative information. Up to now, we lack scientific data on whether these new strategies have been particularly effective in regulating online information. However, the Party-state claims that the new ideological campaign on the Internet has proven efficient. To some

66. Nan Luo Gu Xiang Tour in the microblog of Fan Club of Learning From Xi, www.weibo.com/xuexifensituan?topnav=1\&wvr=6\&topsug=1\&is_search=1\&key_word=\%E5\%8D\%97\%E9\%94\%A3\# _rnd1420504536389 (accessed by 5 January 2015).

67. Microblogs of Fan Club of Learning from Xi, http://weibo.com/u/3043581645?topnav $=1 \& w v r=6 \&$ topsug $=1$ (accessed on 2 January 2015).

68. Picture of $\mathrm{Xi}$ Jinping in the microblog of Fan Club of Learning from Xi, http://weibo.com/ u/3043581645?topnav=1\&wvr=6\&topsug=1\&is_search=1\&key_word=\%E5\%B9\%B3\%E5\%B9 \%B3\#_O (accessed on 5 January 2015).

69. Song Shijing and Li Dandan, "'Rouxing' guanli bannian. Wangluo kongjian 'qinglangqilai'" (Regulating Internet in a Soft Way, Internet Sphere becomes Cleaned), art. cit.

70. Keith B. Richburg, "'Fans' of Xi Jinping Fawn Online Over 'Pingping,' China's New Leader," Washington Post, 12 December 2012, www.washingtonpost.com/world/asia_pacific/xi-fans-fawn-overpingping-chinas-new-leader/2012/12/12/f9aa5334-446f-11e2-8c8f-fbebf7ccab4e_story.html (accessed on 20 May 2015).

71. Ibid.

72. Song Shijing and Li Dandan, "'Rouxing' guanli bannian. Wangluo kongjian 'qinglangqilai'" (Regulating Internet in a Soft Way, Internet Sphere becomes Cleaned), art. cit.

73. Ibid.

74. "From Weibo to Wechat," The Economist, 18 January 2015, www.economist.com/news/china/ 21594296-after-crackdown-microblogs-sensitive-online-discussion-has-shifted-weibo-wechat (accessed on 14 June 2015) 
degree, the new regime has averted extensive public discussion and emotional outpouring towards government deficiencies and social problems. However, given that Chinese netizens have a long record of exposing strategies to regulate the Internet and of breaking through ideological control, we should take a closer look at the future of Chinese cyberspace and whether or not it will become a space purged of critical voices as the new leadership envisages.

Finally, yet critically, while the Party-state has devoted immense effort to managing online public opinion, the decline of critical voices on microblogs might be attributable to other factors as well. One notable one is the emergence and popularity of Tencent's WeChat, a newer generation social networking service aimed at optimising online activity through smart phones. ${ }^{(75)}$

According to a report by the CNNIC, the number of microblog users peaked in 2012 and then began to decline. In 2013, the number of microblog users dropped by $9 \%$ to 280 million, and in 2014 dropped another $7.1 \%$ to 249 million. ${ }^{(76)}$ In comparison, WeChat users burgeoned by $41 \%$ to 500 million in 2014. ${ }^{(77)}$ At the same time, the overall number of Chinese
Internet users increased $9.5 \%$ to 618 million. Therefore, against the background of an accumulation of Chinese Internet users, the boom in WeChat users has come at the expense of a drop in microblog users. The reduction in critical voices and emotional outpouring on microblogs may therefore also be the result of the migration of microblog users to WeChat. ${ }^{(78)} \mathrm{How}$ ever, increasingly draconian controls over microblog information and the shifting of Internet users from microblogs to WeChat should not be understood in isolation. As some scholars have pointed out, compared with microblogs as a public forum, WeChat tends to be a private form of communication designed for sharing information and photos among smaller groups of people. Increasing control over microblogs therefore appears to have forced some people to abandon public forums in favour of private circles to avoid political risk. ${ }^{(79)}$

\section{Angela $\mathrm{Ke} \mathrm{Li}$ is a PhD candidate at Institute of Communication}

Research, University of Illinois at Urbana-Champaign.

810 South Wright Street, 119 Gregory Hall, Urbana, Illinois, 61801, USA (keli5@illinois.edu).

75. Tai Zixue and Liu Xiaolong, "The Chinese Government Hops on the Wechat Bandwagon," China Policy Institute Blog, 6 May 2015, http://blogs.nottingham.ac.uk/chinapolicyinstitute/wechatbandwagon $/$ ?utm_source=rss\&utm_medium=rss\&utm_campaign=chinese-government-hopson-the-wechat-bandwagon2015/05/06/chinese-government-hops-on-the- (accessed on 15 June 2015).

76. "CNNIC: 2014 nian weibo yonghushu da 2.49 yi. Shiyonglü xiajiang 7.1\%" (China Internet Network Information Center: Microblog Users Drop 7.1\% to 249 Million in Total in 2014), China News, 3 February 2015, http://finance.chinanews.com/it/2015/02-03/7030468.shtml (accessed on 14 June 2015).

77. Jia Ru, "Weixin yonghu po 5 yi tong bi zengzhang 41\%" (WeChat Users Total More Than 5 Million, Increasing 41\%), Tai Media, 18 March 2015, http://money.163.com/15/0318/18/ALOQBP LF00253BOH.html (accessed on 14 June 2015).

78. "From Weibo to WeChat," art. cit.

79. Doug Yong, "Chinese Microblogging:Weibos May Be on the Wane," Global Technology, 20 January 2014, http://techonomy.com/2014/01/chinese-microblogging-weibos-may-wane (accessed on 14 June 2015). 